\title{
Sermilik Stationen
}

- vigtig udpost i forståelsen af klimacendringer

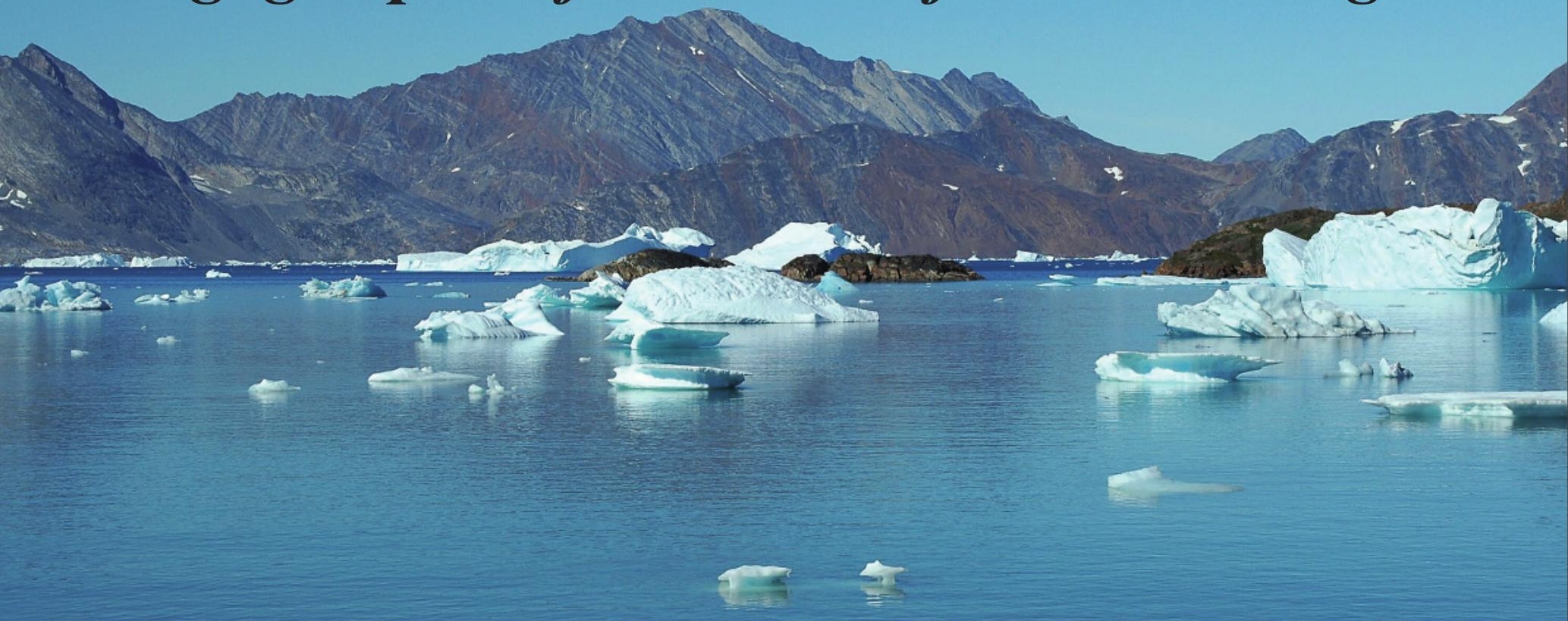

Udsigt fra Sermilik Stationen ud over Sermilik-fjorden. (Foto: Jacob C. Yde)

Af ph.d.-studerende Jacob Clement Yde, Geologisk Institut, Aarhus Universitet, lektor og stationsleder Bent Hasholt, Geografisk Institut, Københavns Universitet, og lektor Niels Tvis Knudsen, Geologisk Institut, Aarhus Universitet.

De seneste årtiers fokus på kommende klimaændringer har betydet en stigende interesse for interaktionen mellem en række processer, der foregår i arktiske egne af kloden.
Hvis Danmark skal opretholde et seriøst engagement inden for dette forskningsområde, er det derfor nødvendigt at bevare, vedligeholde og styrke aktiviteterne ved de grønlandske feltstationer, herunder Sermilik Stationen i Sydøstgrønland.

Sermilik Stationen $\left(65^{\circ} 40^{\prime} \mathrm{N}, 38^{\circ} 10^{\prime} \mathrm{W}\right)$ er beliggende på Ammassalik Ø ca. $20 \mathrm{~km}$ nordvest for byen Tasiilaq (tidligere Ammassalik).
Vejr og geologi omkring stationen Området omkring stationen byder på en suite af landskabssystemer som gletschere, isdæmmede søer, aktive og inaktive smeltevandssletter, moræner, en tidevandsflade, jordbundsudvikling og periglaciale landskabsformer. Grundfjeldet i området består hovedsageligt af hypersthen-holdig diorit og granodiorit tilhørende Ammassalik intrusivkomplekset samt senere dannet granatrig gnejs.

Den årlige middeltemperatur er $-1,6^{\circ} \mathrm{C}$, mens sommermiddeltemperaturen når op

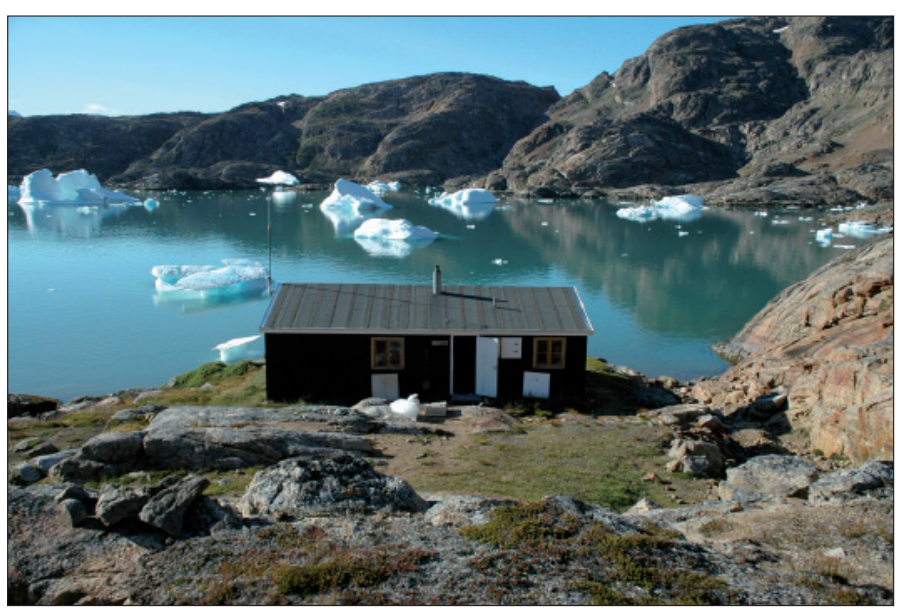

Sermilik Stationen. (Foto: Jacob C. Yde)

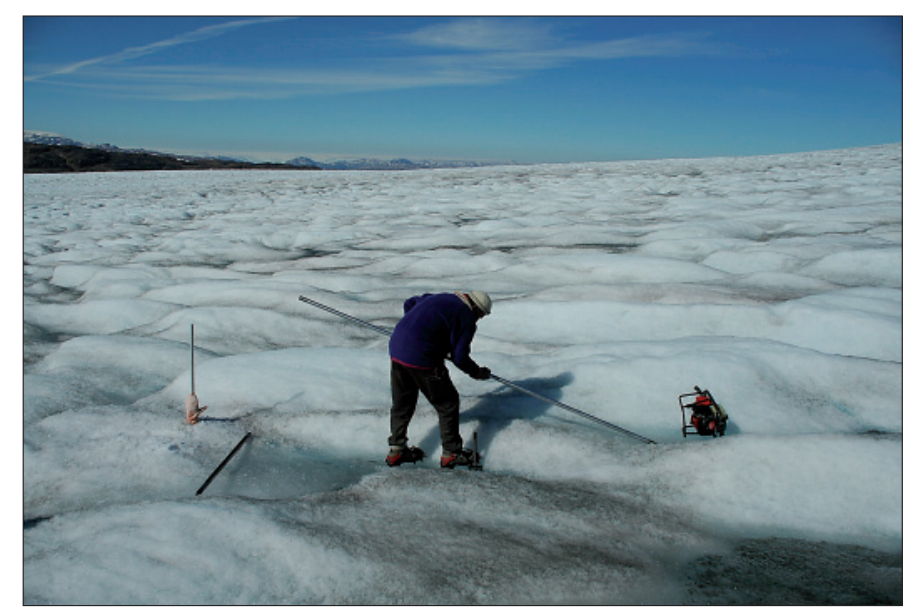

Boring af stager på Mittivakkat Gletscheren. (Foto: Jacob C. Yde) 

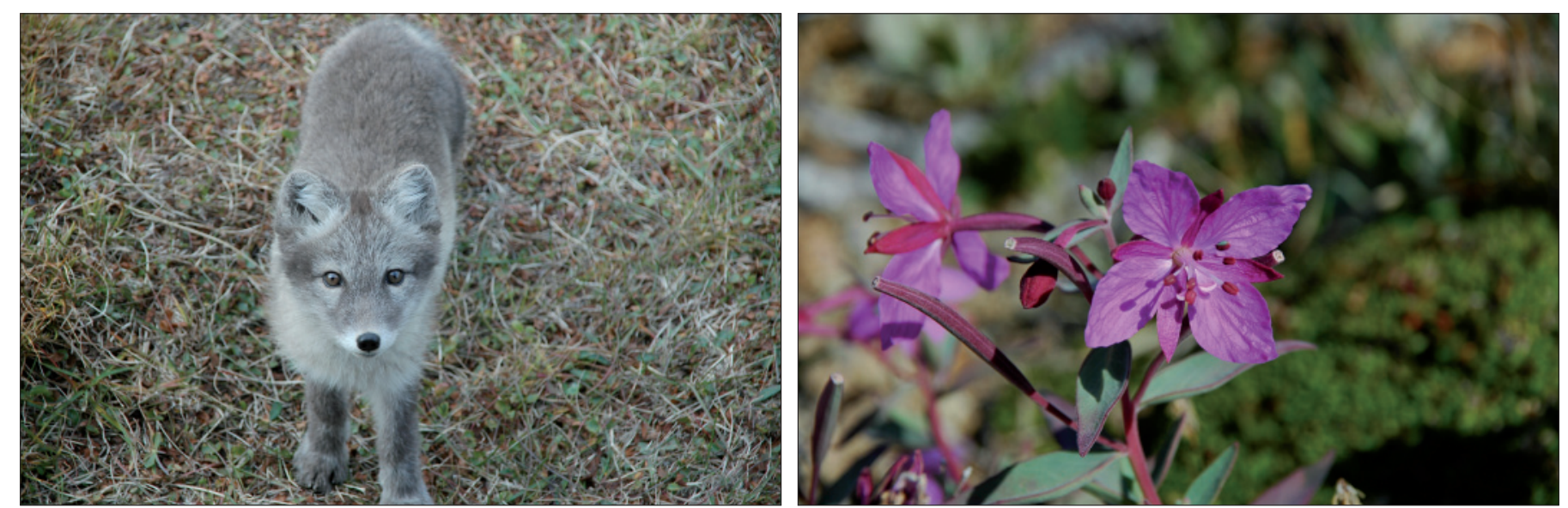

Nysgerrig blårcevehvalp. Til højre ses den storblomstrede gederams, som er Grønlands nationalblomst. På grønlandsk hedder den Niviarsiaq, hvilket betyder lille pige. (Fotos: Jacob C. Yde)

på $6,6^{\circ} \mathrm{C}$. Den årlige nedbørsmængde er $\mathrm{i}$ gennemsnit $983 \mathrm{~mm}$, hvor kun en lille del falder om sommeren. Foruden årlige og sæsonmæssige variationer bevirker de høje fjelde på op til $1.096 \mathrm{~m}$ og den relativt korte afstand til Indlandsisen, at der opstår store lokale klimatiske forskelle.

Fra Tasiilaq kan stationen nås til fods på 4-5 timer, hvis man finder en villig taxichauffør, der tør forcere de første $7 \mathrm{~km}$ på en nødtørftigt vedligeholdt grusvej ud til den nyligt opdæmmede 168-sø. Ofte kræver et længere ophold, at en båd chartres til transport af større mængder udstyr, brændstof og forplejning, men selv om sommeren kan storisen pakke tæt mod land og i kortere perioder umuliggøre sejlads. Et alternativ hertil er helikoptertransport, som er relativt dyr. Stationen har helikopterlandingsplads $i$ haven, et nogenlunde fladt græsdækket areal bag stationen.

\section{Stationens historie}

I forbindelse med det danske bidrag til det internationale geofysiske år, 1957-58, blev der i perioden 1956-58 udført glaciologiske og hydrologiske undersøgelser ved Mittivakkat Gletscheren (tidligere Mitdluagkat) under ledelse af den danske polarforsker Børge Fristrup fra Geografisk Institut, Kø- benhavns Universitet. Det øgede interessen for etableringen af en forskningsstation i Østgrønland. I 1970 blev den første Sermilik Station rejst i den nuværende have i læ for piteraq'en, den stærke vind ved Tasiilaq på over $100 \mathrm{~m} / \mathrm{s}$, der kan opstå som følge af lavtrykspassager syd om Grønland. Men allerede i 1972 blev stationen ødelagt af et sneskred efter stort snefald under en piteraq. Den nuværende station på $60 \mathrm{~m}^{2}$ blev opført i 1973-74 nærmere ved kysten. I 1993 blev stationens værksted udvidet med et $20 \mathrm{~m}^{2}$ depot og vaskerum, og i 2003 blev et særskilt brændstofdepot bygget.

Sermilik Stationen er ikke fast bemandet, men det er muligt for op til 6 forskere at opholde sig på stationen gennem længere tid. Frisk vand fås fra en kilde tæt ved hovedbygningen eller fra smeltning af sne. Isskosser kan hives op fra Sermilik Fjorden og bruges til at holde fødevarer afkølede. En $4,5 \mathrm{~kW}$ generator leverer $220 \mathrm{~V}$ elektricitet, og opvarmning af stationen sker med olieovn.

Det lokale tilsyn med stationen er i over 25 år blevet udført af Mogens B. Kofoed fra Tasiilaq. Det er også ham og hans familie, der to gange har observeret isbjørne ved stationen. Senest i 2002 hvor han nedlagde en ung han. Bortset fra irriterende myg og fluer og et nysgerrigt blårævekuld er dyrelivet i området sparsomt. De hyppigst forekommende er snespurve, ryper, måger, ravne og enkelte vadefugle samt fjeldørred og sæler.

\section{Forskningsaktiviteter}

Forskningen ved stationen har primært været fokuseret på konsekvenserne af klimaændringer i Arktis. Derfor er baggrundsmonitering vigtig for mere specifikke undersøgelser. Over en årrække er der indsamlet klimadata fra to automatiske klimastationer; en i 28 m.o.h. ved stationen (siden 1997) og en i 515 m.o.h. på en nunatak (isfri klippe) på Mittivakkat Gletscheren (siden 1993).

Samtidig er der på gletscheren foretaget massebalancemålinger, dvs. sondemålinger af sneakkumulationen om foråret og stagemålinger af isafsmeltningen sidst på sommeren. Det er Grønlands længstvarende og i øjeblikket eneste fortløbende massebalanceserie, hvilket gør den særlig vigtig for klimamodellering. Resultater herfra viser, at gletscherens volumen er mindsket med $5 \%$ i løbet af de sidste 10 år. Derfor kan man forvente, at Mittivakkat Gletscheren og mange af de andre mindre gletschere i Østgrønland, der ikke er udløbere fra Indlandsisen, smelter bort inden for de kommende

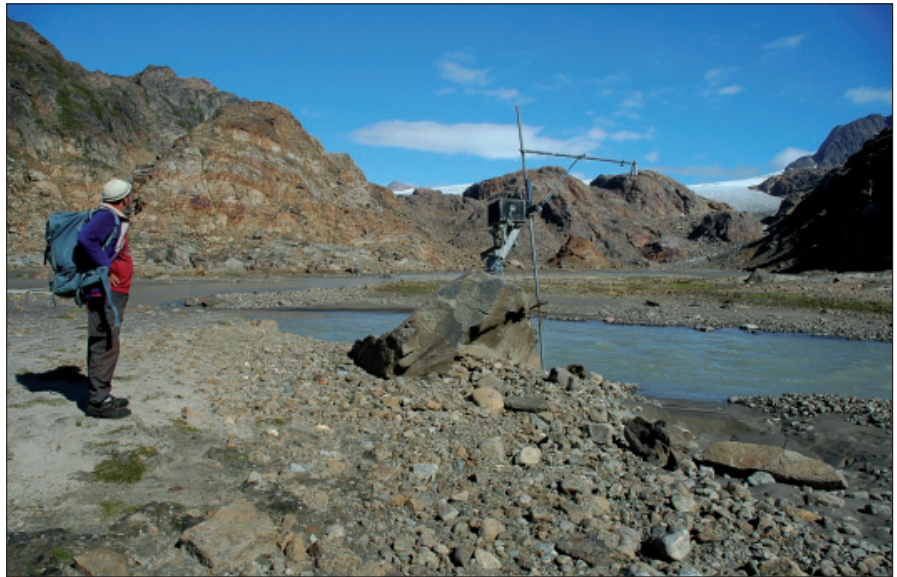

Hydrometrisk station i dalen foran Mittivakkat Gletscheren. (Foto: Jacob C. Yde)

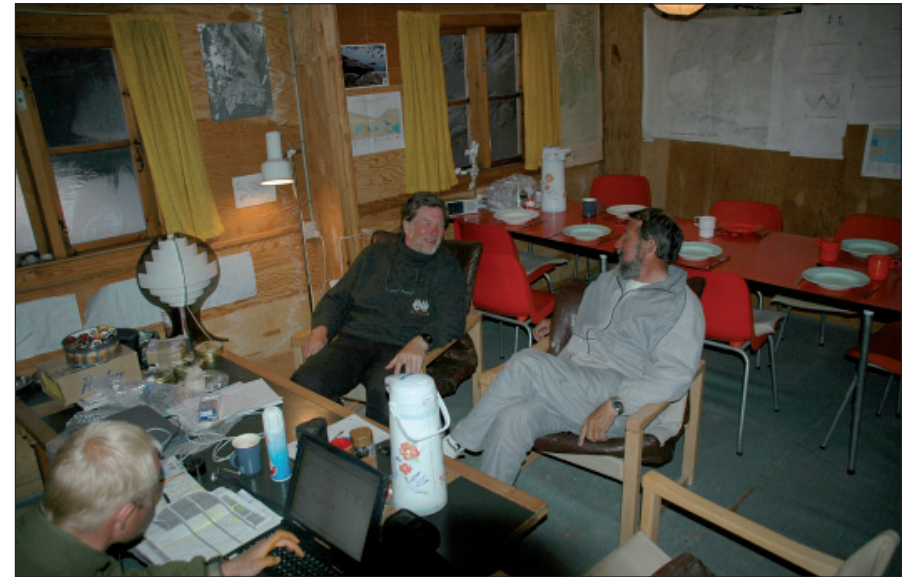

Aftenhygge og databearbejdning i Sermilik Stationens stue. (Foto: Jacob C. Yde) 


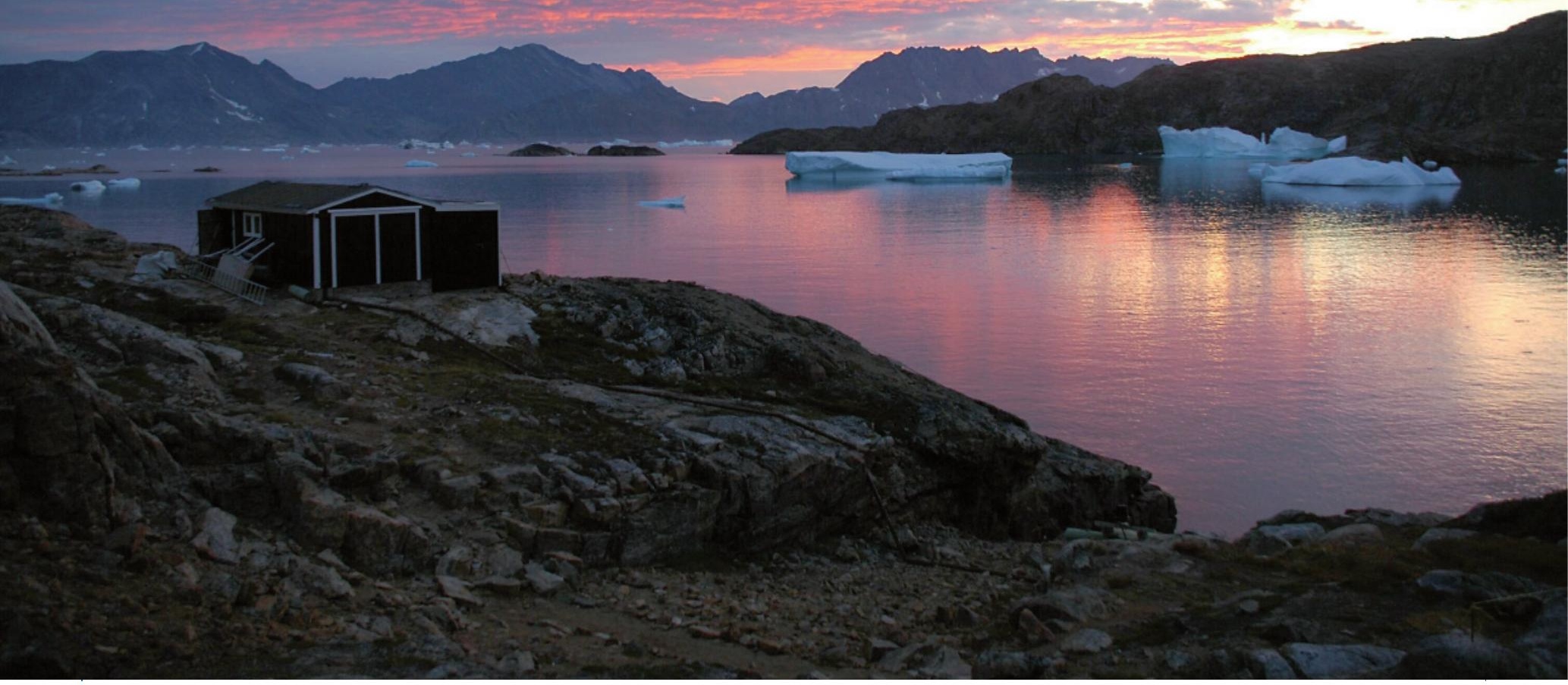

Solnedgang over Sermilik Stationens varksted. (Foto: Jacob C. Yde)

200-300 år, hvis den nuværende klimaudvikling fortsætter.

Sedimenttransporten i østgrønlandske gletschere er lav, så gletscheroverfladen på de nederste dele dækkes ikke med et beskyttende sedimentlag. Det betyder, at ændringer i klimaet let påvirker disse gletschere. Den øjeblikkelige tilbagesmeltning giver sig til kende ved, at plantemateriale, som sandsynligvis blev isdækket før og under den lille istid, kommer til syne langs isranden.

I elven neden for gletscheren er vandføringen moniteret gennem mange år. I 2004 blev endnu en automatisk hydrometrisk station opsat tættere ved gletscherfronten, så det proglaciale bidrag bedre kan differentieres fra det glaciale. Sedimenttransport og den hydrokemiske sammensætning i smeltevandet har givet en forståelse af den fysiske og kemiske forvitring, som kan ekstrapoleres til andre områder i Østgrønland med samme geologi og glaciationsratio.

Der mangler dog stadig viden om, hvordan de enkelte processer fungerer og eventuelt påvirker hinanden. Eksempelvis er det endnu ikke entydigt, hvilken rolle ændringer i smeltevandsmængden og ændringer i gletscheres dræningssystem har for $\mathrm{CO}_{2}$ kreds- løbet. Det er heller ikke klart, hvor aktiv den mikrobiologiske forvitring er på overfladen af, under og foran gletschere.

\section{Undervisning af studerende}

Sermilik Stationen har også været udgangspunkt for undervisning af studerende $i$ arktiske aspekter af hydrologi, kystmorfologi, klimatologi og jordbundslære samt arktiske discipliner som glaciologi, permafrost og periglaciale processer. Geografisk Institut, København, har flere gange afholdt hovedfagskursus for studerende på stationen, senest i 2005.

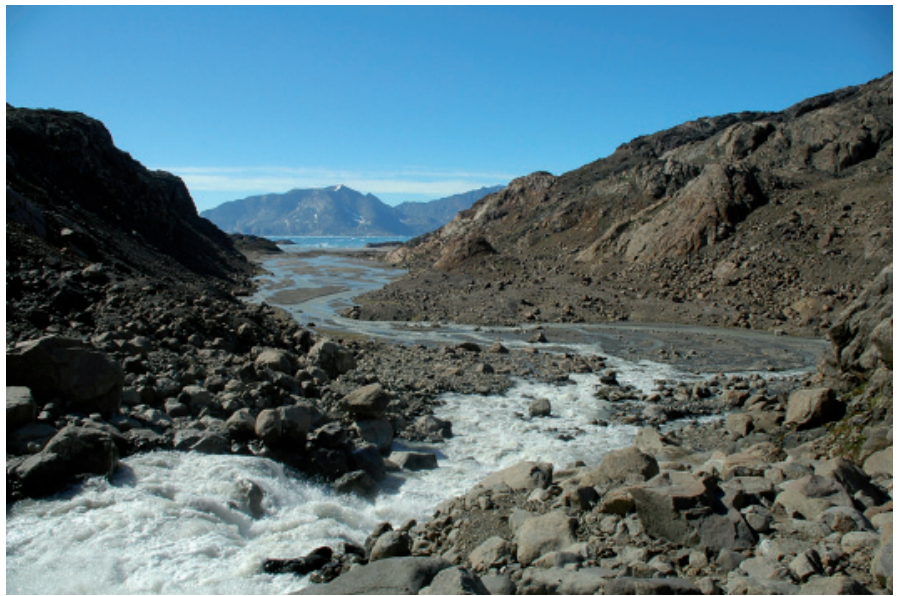

Smeltevandssletten foran Mittivakkat Gletscheren. (Foto: Jacob C. Yde)

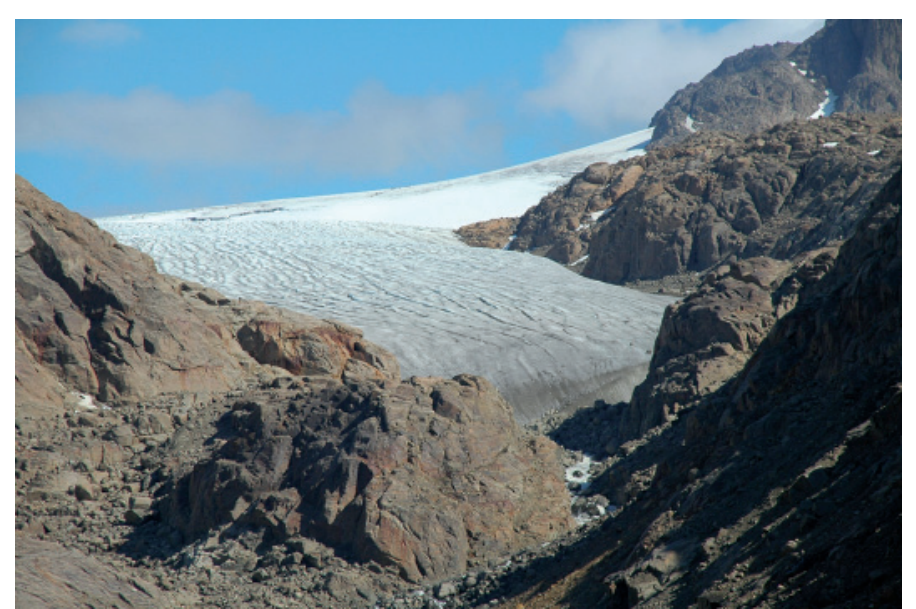

Mittivakkat Gletscherens tunge. De bare klipper foran gletscheren er blevet blotlagt inden for de seneste årtier. (Foto: Jacob C. Yde) 


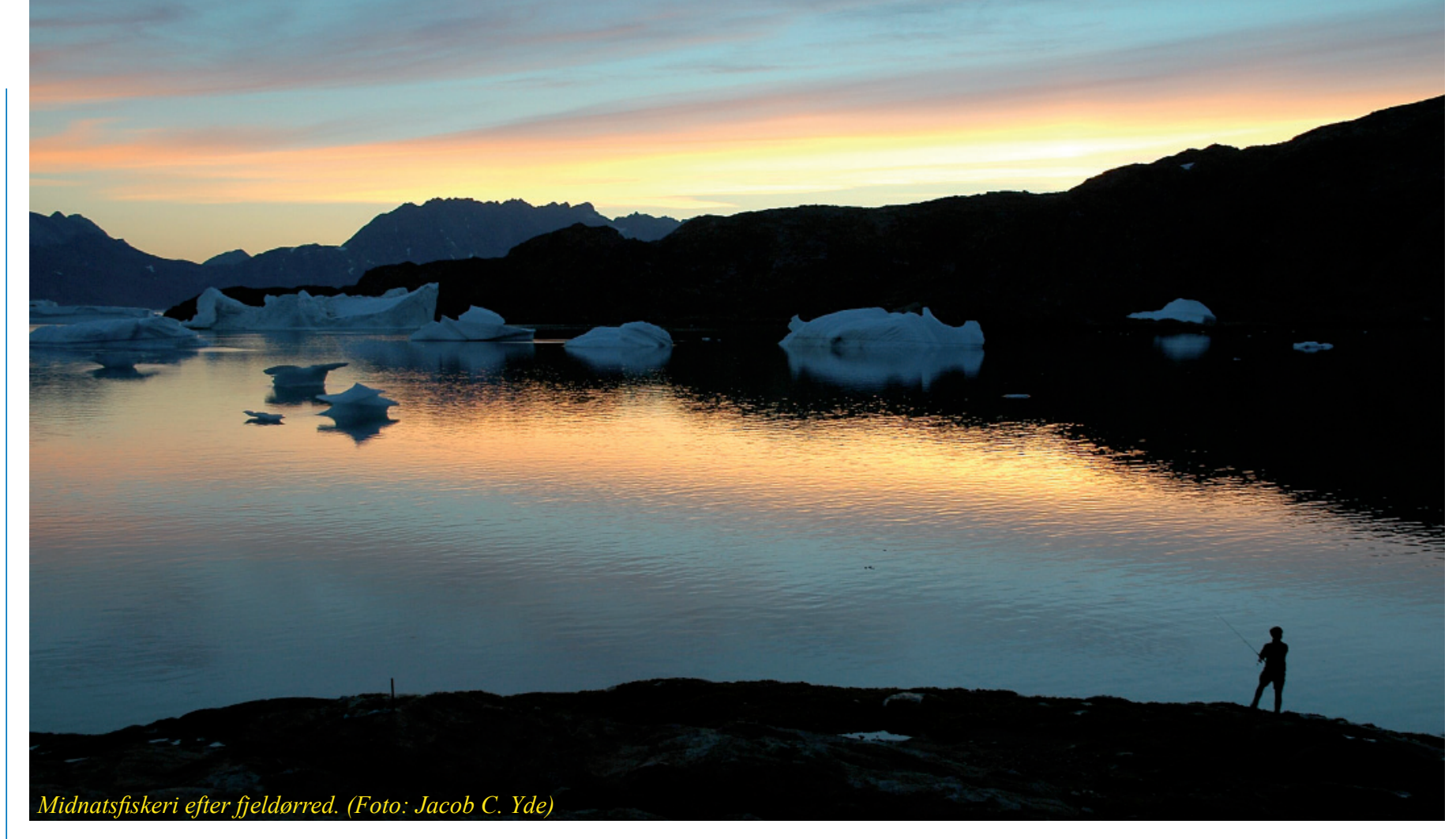

Aktiviteterne ved Sermilik Stationen spænder bro mellem klimaudviklingen i Arktis og de relaterede ændringer i hydrologiske og glaciologiske processer. Hvis Danmark ønsker at bevare et højt vidensniveau vedrørende klimaudvikling, er det derfor vigtigt at bibeholde og styrke både forsknings- og undervisningsindsatsen ved de grønlandske feltstationer.

\section{Yderligere information}

Sermilik Stationen ejes af Det Naturvidenskabelige Fakultet ved Københavns Universitet.

Den daglige drift varetages af Geografisk Institut, KU.

Ønskes yderligere information, kan henvendelse ske til:
Stationsleder Bent Hasholt

Geografisk Institut

Københavns Universitet

Øster Voldgade 10

1350 København K

Telefon 35322500

E-mail: bh@geogr.ku.dk 